\title{
Redes de Organizações da Sociedade Civil: Proposição de uma ferramenta de análise
}

\author{
Civil Society Organizations Networks: Proposing an analysis tool \\ Redes de Organizaciones de la Sociedad Civil: Proponiendo una herramienta de análisis
}

Recebido: 18/01/2021 | Revisado: 21/01/2021 | Aceito: 25/01/2021 | Publicado: 31/01/2021

\author{
Oswaldo Gonçalves Junior \\ ORCID: https://orcid.org/0000-0002-3033-3741 \\ Universidade Estadual de Campinas, Brasil \\ E-mail: oswaldo.junior@fca.unicamp.br \\ Ana Carolina Spatti \\ ORCID: https://orcid.org/0000-0001-8839-8276 \\ Universidade Estadual de Campinas, Brasil \\ E-mail: anaspatti@ige.unicamp.br \\ Keyla Ketlyn Passos Pimenta \\ ORCID: https://orcid.org/0000-0002-4017-5564 \\ Universidade Estadual de Campinas, Brasil \\ E-mail: keyla.pimenta@fca.unicamp.br \\ Priscila Martins Baia \\ ORCID: https://orcid.org/0000-0002-1710-0935 \\ Universidade Estadual de Campinas, Brasil \\ E-mail: priscila.baia@ fca.unicamp.br
}

\begin{abstract}
Resumo
Este artigo tem como objetivo caracterizar perfis de gestão e atuação de Organizações da Sociedade Civil (OSCs) conformadas em redes voltadas para o desenvolvimento social. Trata-se de um estudo de caso que analisa, comparativamente, 20 OSCs, tomando como ponto de partida dimensões analíticas relacionadas ao planejamento e execução de atividades, direção e controle, e seleção de membros para compor a organização. O estudo identifica que a atuação das OSCs pode ser entendida a partir de dois parâmetros: (i) governança estratégica, isto é, incidência política da organização, cujo foco de atuação se dá na sensibilização e mobilização de um público-alvo para com determinada causa; e (ii) atuação de base, ou seja, a atuação das organizações na implementação de programas, projetos e/ou ações em nível de rua ou in loco. Baseando-se nesses parâmetros, propõe-se uma matriz teóricoconceitual que categoriza a atuação das OSCs em quatro perfis: Perfil Regulador; Perfil Impreciso; Perfil Híbrido; e Perfil Linha de Frente. A matriz pode servir como ferramenta para uma distribuição mais eficiente dos recursos por parte do poder público, identificando OSCs que sejam dotadas das características que darão melhor capilaridade e eficiência para prestação do serviço desejado. A capacidade de um governo de reconhecer o perfil das OSCs que atuam em seu território permite traçar arranjos que fortaleçam sua atuação. Logo, os achados estimulam reflexões teóricas e investigações empíricas que ampliam o conhecimento sobre o fenômeno, abrindo possibilidades para estudos sobre redes em perspectivas e contextos distintos.
\end{abstract}

Palavras-chave: Redes; Organizações da sociedade civil; Matriz situacional.

\begin{abstract}
This article aims to characterize management and performance profiles of Civil Society Organizations (CSOs) formed in networks aimed at social development. A case study analyze 20 CSOs comparatively, taking as starting point analytical dimensions related to the planning and execution of activities, direction and control, and selection of members to compose the organization. The study identifies that the performance of CSOs can be understood from two parameters: (i) strategic governance, that is, the political influence of the organization, whose focus is on raising awareness and mobilizing a target audience for a given cause; and (ii) grassroots performance, that is, the performance of organizations in the implementation of programs, projects and/or actions at street level or in loco. Based on these parameters, a theoretical-conceptual matrix that categorizes the performance of CSOs in four profiles is proposed: Regulatory Profile; Inaccurate profile; Hybrid Profile; and Frontline Profile. The matrix can serve as a tool for a more efficient distribution of resources by the State, identifying CSOs that are endowed with the characteristics that will provide better capillarity and efficiency to provide the desired service. The ability of a government to recognize the profile of CSOs operating in its territory allows it to outline arrangements that strengthen its performance. Therefore, the findings stimulate theoretical reflections and empirical investigations that expand knowledge about the phenomenon, opening up possibilities for studies on networks in different perspectives and contexts.
\end{abstract}

Keywords: Networks; Civil society organizations; Situational matrix. 


\begin{abstract}
Resumen
Este artículo tiene como objetivo caracterizar los perfiles de gestión y desempeño de las Organizaciones de la Sociedad Civil (OSC) formadas en redes orientadas al desarrollo social. Se trata de un estudio de caso que analiza 20 OSC comparativamente, tomando como punto de partida dimensiones analíticas relacionadas con la planificación y ejecución de actividades, dirección y control, y selección de miembros para componer la organización. El estudio identifica que el desempeño de las OSC se puede entender a partir de dos parámetros: (i) la gobernanza estratégica, es decir, la influencia política de la organización, cuyo foco está en la sensibilización y movilización de un público objetivo por una causa determinada; y (ii) el desempeño de base, es decir, el desempeño de las organizaciones en la implementación de programas, proyectos y / o acciones a pie de calle o in loco. Con base en estos parámetros, se propone una matriz teórico-conceptual que categoriza el desempeño de las OSC en cuatro perfiles: Perfil Regulatorio; Perfil inexacto; Perfil híbrido; y Perfil de primera línea. La matriz puede servir como una herramienta para una distribución más eficiente de los recursos por parte del poder público, identificando las OSC que están dotadas de las características que brindarán una mejor capilaridad y eficiencia para brindar el servicio deseado. La capacidad de un gobierno para reconocer el perfil de las OSC que operan en su territorio le permite delinear arreglos que fortalecen su desempeño. Por tanto, los hallazgos estimulan reflexiones teóricas e investigaciones empíricas que amplían el conocimiento sobre el fenómeno, abriendo posibilidades para estudios sobre redes en diferentes perspectivas y contextos.
\end{abstract}

Palabras clave: Redes; Organizaciones de la sociedad civil; Matriz situacional.

\title{
1. Introdução
}

As Organizações da Sociedade Civil (OSCs) emergiram no contexto de ascensão da ideologia neoliberal e modificaram a dinâmica de participação e articulação entre os atores da sociedade civil, que percebem na colaboração participativa um meio de realizar transformações sociais (Goulart et al., 2010). Por representarem diversos esforços de ação coletiva, intervenção política, prestação de serviços sociais e atividades de vigilância sobre os setores governamentais e empresariais (Appe \& Barragán, 2017), as OSCs têm se tornado atores cada vez mais influentes no desenvolvimento nacional, especialmente em países em desenvolvimento (Stephen, 2011), promovendo mudanças em diversos âmbitos da sociedade, como o cultural, econômico, social e político (Motta, Junqueira \& Turra, 2018; Lopez, 2018).

Principalmente a partir da década de 1980, o Estado brasileiro transfere ao terceiro setor a execução de alguns elementos das políticas públicas. Tais relações entre poder público e OSCs vêm no sentido de apostar num tipo de gestão social mais descentralizada, a fim de alcançar as populações periféricas utilizando da capilaridade, ou mesmo da expertise, que as OSCs possuem, aumentando o tecido social que protege e serve as comunidades (Stefani \& Junqueira, 2013).

Operando nos níveis local, regional, nacional e internacional e pautadas por uma cidadania ativa, as OSCs se organizam em redes colaborativas para a troca de informações, articulação institucional/política e para a implementação de projetos comuns (Goulart et al., 2010; Olivieri, 2003). A articulação das OSCs em redes é uma característica desse tipo de organização (Olivera \& Haddad, 2001; Pinto \& Junqueira, 2009). Embora não haja uma definição conclusiva do termo redes (Goulart, Vieira, Costa \& Knopp, 2010), sendo as definições vagas o suficiente para acomodar uma enorme diversidade de tipologias (JMJ Angola, 2009), é possível identificar alguns aspectos-chave comuns na literatura, dos quais partiram o enquadramento teórico deste trabalho.

Uma rede pode ser definida como um conjunto de nós interligados entre si por meio de linhas (Martinho, 2003; Haesbaesrt, 2006). Os nós podem representar um indivíduo, um grupo de indivíduos ou uma organização. Já as linhas representam as diferentes formas de relação recíproca entre os nós e são responsáveis por conferir dinamicidade e conectividade ao arranjo (Martinho, 2003). As redes são estruturas complexas, pautadas por valores e/ou objetivos comuns, sendo predominantemente descentralizadas (Souza \& Quandt, 2008; Amaral, Justen \& Fernandes, 2003; Mañas, 2000). Articulam-se em torno da identificação de situações-problema pelos atores participantes (Minhoto \& Martins, 2001), que partilham um determinado espaço social, geográfico ou se envolvem em um evento específico (Newman, 2003). Logo, as redes podem variar desde pequenos conglomerados, formais ou informais, até organizações mais institucionalizadas (Amundsen \& Abreu, 2007; JMJ Angola, 2009; Alvear, 2008). 
A importância das OSCs, potencializada por sua atuação em redes de colaboração, expressa-se também no crescente interesse acadêmico no tema (Mendonça, Alves \& Nogueira, 2016). Apesar disso, o perfil das organizações, o escopo e a natureza de suas iniciativas carecem de estudos detalhados (Lopez, 2018; Mello, Pereira \& Andrade, 2019).

Reconhecendo esta lacuna, este artigo tem como objetivo caracterizar perfis de gestão e atuação de OSCs conformadas em redes voltadas para o desenvolvimento social. Fruto de uma pesquisa maior desenvolvida pelos autores junto à Fundação Itaú Social, são analisadas vinte experiências e detalhadas suas formas de gestão, seus modus operandi, seus mecanismos de financiamento e de sustentabilidade econômico-financeira. Os resultados do estudo possibilitaram a construção de uma ferramenta para traçar perfis de atuação das OSCs num panorama articulado, contribuindo para apoiar o poder público no desenho e na implementação de políticas públicas mais efetivas e para suscitar novos insights de pesquisa sobre o tema. Portanto, este estudo oferece informações que permitem compreender, a nível micro, como cada organização se estrutura e se organiza e, a nível macro, como o campo se mobiliza.

Para tanto, este artigo organiza-se em três seções para além desta introdução e da conclusão. A primeira seção referese aos procedimentos metodológicos. A segunda, à sistematização das características identificadas a partir das experiências analisadas sob três dimensões: (i) organização institucional; (ii) sustentabilidade financeira; e (iii) programas, projetos e ações. A terceira, por sua vez, refere-se à identificação de perfis de atuação em rede considerando as análises anteriores e apresentando a ferramenta proposta, denominada como Matriz Situacional.

\section{Metodologia}

Este é um estudo de caso de cunho qualitativo, o que se justifica pela necessidade de descrever e analisar as experiências da forma mais detalhada possível (Pereira et al., 2018). Os procedimentos metodológicos dividem-se em dois momentos. O primeiro, denominado "Quem", visa explicar como foram selecionadas as organizações e quem são. O segundo, "Como", dedica-se a descrever os critérios para analisar essas organizações de modo sistemático e comparado.

\section{1 "Quem"}

Foram dois os critérios metodológicos utilizados para seleção das organizações. O primeiro relaciona-se ao entendimento teórico-conceitual sobre a definição de OSCs que, para efeitos deste artigo, foram entendidas como entidades privadas, não vinculadas jurídica ou legalmente ao Estado, sem fins lucrativos e autônomas do ponto de vista administrativo.

Considerando que esta pesquisa se valeu apenas de dados secundários, o segundo critério refere-se à disponibilidade das informações, de modo que a visibilidade online das OSCs foi tomada como regra para a seleção daquelas a serem estudadas. Isto é, o recorte inicial exigiu que as organizações apresentassem, minimamente, informações disponíveis na internet, em sítios eletrônicos institucionais, redes sociais, estatutos, trabalhos acadêmicos, relatórios avaliativos, regulamentos internos e auditorias internas e externas.

Respeitados esses critérios iniciais, o mapeamento das organizações contou também com o instrumento denominado SnowBall Sampling (Bola de Neve), com algumas adaptações ao campo de trabalho. De maneira simplificada, o instrumento consiste em "uma técnica para encontrar sujeitos de pesquisa. Um sujeito fornece ao pesquisador o nome de outro sujeito que, por sua vez, fornece o nome de um terceiro e assim por diante" (Vogt \& Johnson, 1999, p. 368, tradução nossa). De acordo com Clements, Darroch e Green (2017, p. 12, tradução nossa), essa metodologia "oferece uma estrutura robusta para medir a performance de pesquisa e sua relativa troca e análise de dados, fornecendo uma abordagem consistente à informação e mensuração entre instituições, financiadores e corpos governamentais".

Esse instrumento sofreu adaptações para esta pesquisa em dois sentidos: primeiro, porque não houve contato direto com os objetos de pesquisa, nesse caso, as OSCs; segundo, porque, na prática, as experiências foram selecionadas levando em 
consideração uma busca ampla, parcerias que as entidades possuíam e a referência da organização em seu campo de atuação. Ao observar a rede de parceiros, uma organização "levava à outra". A Figura 1 ilustra os procedimentos metodológicos tomados e as organizações selecionadas.

Figura 1. Critérios e técnica de seleção das OSCs.

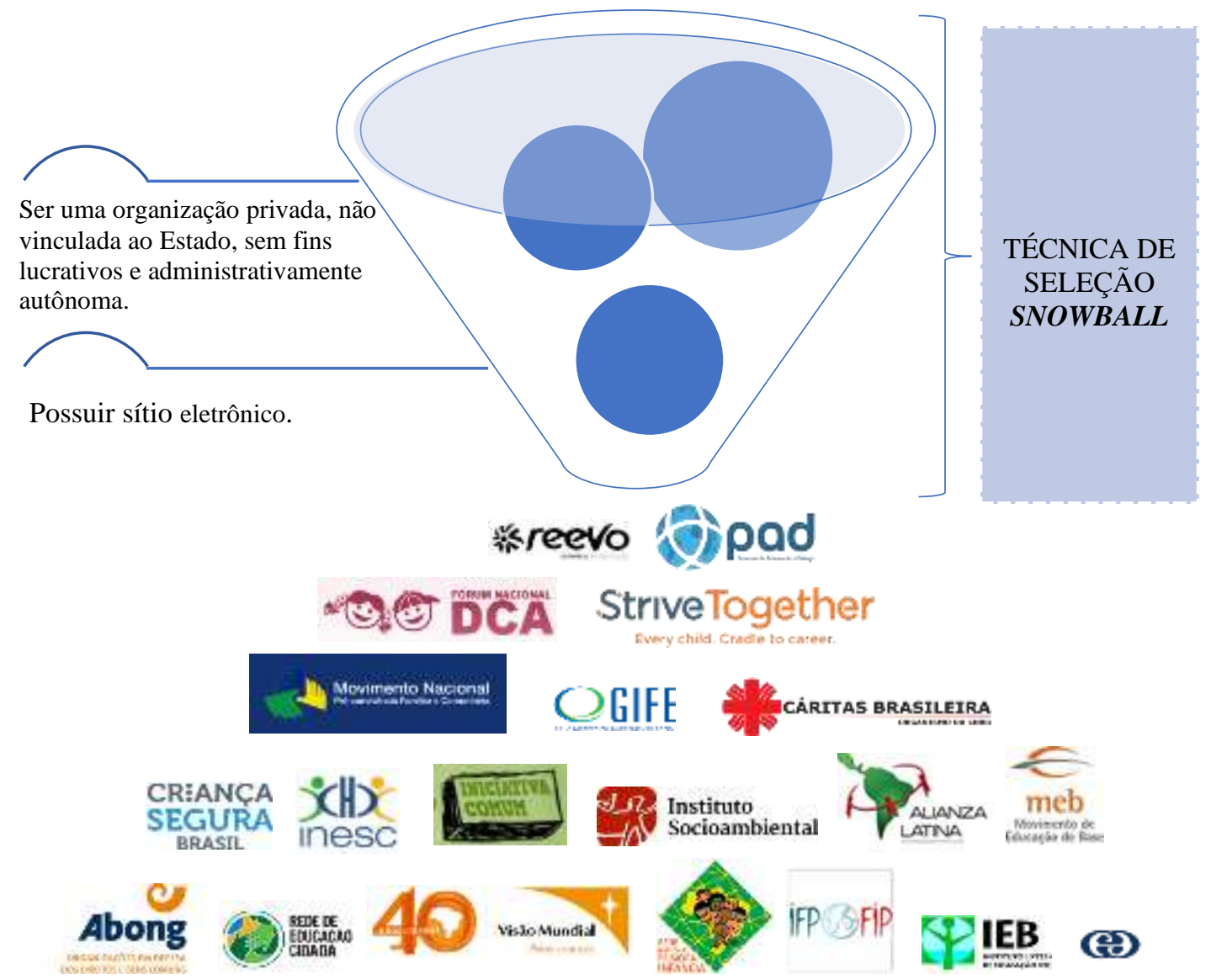

Fonte: Autores.

A escolha metodológica se reflete na multiplicidade das entidades selecionadas que, por sua vez, também não se limitaram a OSCs nacionais: (1) Instituto de Estudos Socioeconômicos (INESC); (2) Instituto Socioambiental (ISA); (3) Grupo de Instituto, Fundações e Empresas (GIFE); (4) Alianza Latina; (5) Movimento de Educação de Base (MEB); (6) Fundação Grupo Esquel Brasil (FGEB); (7) Associação Brasileira de Organizações não Governamentais (ABONG); (8) Visão Mundial; (9) Instituto Internacional de Educação do Brasil; (10) Cáritas Brasileira; (11) Fórum Nacional Permanente de Entidades nãogovernamentais de Defesa dos Direitos da Criança e do Adolescente (Fórum DCA/Rede DCA); (12) Red de Educación Alternativa (REEVO); (13) Criança Segura Brasil; (14) Rede Nacional Primeira Infância; (15) Movimento Nacional Pró Convivência Familiar, Comunitária do Brasil (Movimento Nacional CFC); (16) Fundo Iniciativa Comum; (17) Processo de Articulação e Diálogo (PAD); (18) Rede De Educação Cidadã (RECID); (19) Fórum Internacional de Plataformas Nacionais de ONGs; e (20) StriveTogether.

Com efeito, há uma variedade de subtemas, dentro do tema de desenvolvimento social, abarcada pelas organizações selecionadas: educação; formas de aprendizagem; práticas alternativas de educação; saúde; assistência social; direitos humanos; igualdade social; promoção sociocultural; desenvolvimento de base; exercício da cidadania; mobilização social; combate à pobreza e discriminação; radicalização da democracia; formação sociopolítica; articulação e monitoramento das 
políticas públicas; desenvolvimento sustentável; mudanças climáticas e combate à desertificação; manejo de recursos naturais; e gestão ambiental e territorial.

\section{2 "Como"}

Uma vez selecionadas as experiências, foram definidos critérios de análise que funcionaram como lentes para nortear o olhar sobre os casos: i) Organização institucional (natureza jurídica, formas de gestão, composição dos membros e comunicação e transparência); ii) Sustentabilidade financeira; e (iii) Programas, projetos e/ou ações implementadas pelas OSCs. Isto, a partir de uma abordagem analítico-descritiva, o que permitiu um olhar mais aprofundado para as organizações.

\section{Resultados}

\subsection{Organização Institucional}

A dimensão Organização Institucional explora as práticas de atuação em rede em seu nível organizacional, ou seja, relacionadas às atividades de gestão. Nela, são tratadas questões ligadas à natureza jurídica, formas de gestão, composição dos membros e comunicação e transparência.

\subsubsection{Natureza jurídica}

Entende-se por natureza jurídica de constituição a forma legal assumida pelas entidades a fim de gerenciarem suas atividades. É prática relevante a ser observada em razão de suas múltiplas implicações enquanto elemento facilitador ou de entrave à consecução dos objetivos das experiências. A forma jurídica diferencia legalmente a organização das unidades que a compõe, conferindo a ela aptidão para adquirir e exercer direitos, bem como contrair obrigações.

Das 20 experiências em rede analisadas, 14 possuíam personalidade jurídica, 4 não possuíam e para as 2 restantes não foi possível determinar (Figura 2).

Figura 2. Organizações analisadas, por natureza jurídica.

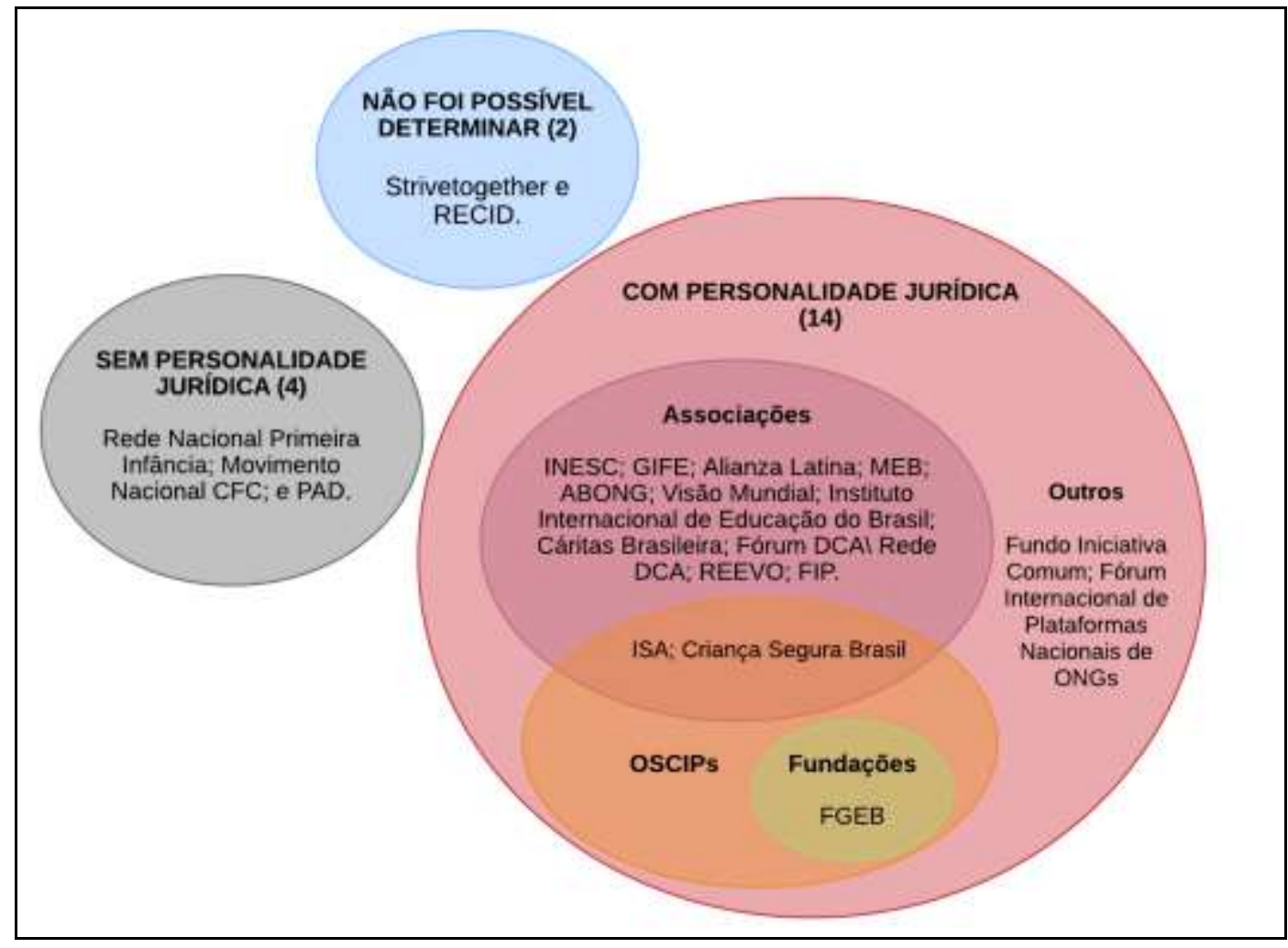

Fonte: Autores. 
Dentre as redes que possuíam personalidade jurídica, há as que tinham um único Cadastro Nacional de Pessoa Jurídica (CNPJ) para a articulação e uma, em especial, que possuía inúmeros CNPJs. As organizações com CNPJ podem assumir a forma de Associações Privadas ou Fundações Privadas. Ambas as formas são organizações não governamentais sem fins lucrativos, porém, as Associações Privadas são constituídas pela união de pessoas, enquanto as Fundações são constituídas por uma dotação de bens. Assim, no âmago de suas constituições figuram as pessoas para as associações e o patrimônio para as fundações. Dentre as 14 experiências estudadas que possuem personalidade jurídica nacional, 11 são Associações Privadas e 1 é Fundação Privada; as outras 2 possuem personalidade jurídica de caráter internacional.

As Redes também podem buscar registros facultativos perante o Poder Público. Tais registros conferem vantagens às organizações, como a facilitação na captação de investimentos privados, obtenção de financiamentos, acesso a benefícios fiscais e a recursos públicos. Dentre as redes estudadas, 3 possuíam registro facultativo como Organização da Sociedade Civil de Interesse Público (OSCIP): o Instituto Socioambiental, a organização Criança Segura Brasil e a Fundação Grupo Esquel Brasil.

A atribuição de personalidade jurídica às entidades é uma prática facilitadora para a pactuação de acordos em geral, principalmente quando necessária a participação da articulação no pleito de subsídios por parte do Estado. As redes que não possuem personalidade jurídica acabam por delegar aos seus membros a formalização de pactos para recebimento de recursos, exigindo deles o cumprimento de uma série de condições legais e estruturais (CNPJ, certidões de débito etc.) para compor a rede. Essas exigências podem gerar um problema significativo, dada a dificuldade dos membros menos institucionalizados promoverem sua formalização e, de fato, atuarem junto aos seus pares na rede.

Um exemplo de experiência cuja falta de personalidade jurídica acarretou nessas dificuldades é o Fundo Iniciativa Comum. O Fundo é um instrumento orçamentário que visa vincular recursos à implementação de programas. Para atingir seu objetivo, exige certos requisitos para participação, como Estatuto Social, ata de eleição dos representantes legais, certidão negativa de débito junto ao Fundo de Garantia por Tempo de Serviço (FGTS) e Instituto Nacional de Seguro Social (INSS) e cópia de CNPJ, bem como o envio de outros documentos ao longo do tempo para o acompanhamento da implementação dos programas. Tais exigências levaram 5 dos 25 grupos selecionados a se retirarem da articulação, por demonstrarem dificuldade até mesmo na obtenção de informações simples, como o número de conta bancária (Martinho, 2013, p. 29).

Já a organização Visão Mundial parece ter inovado ao possuir diversos CNPJs. A prática adotada consiste em criar diversas filiais e a elas conferir personalidades jurídicas distintas, a fim de dar maior elasticidade e descentralização para efetivação de parcerias e contratos em geral, além de driblar a necessidade de alta institucionalização dos participantes da rede para a delegação de atividades ou repasse de recursos.

Tais práticas referentes à atribuição, ou não, de personalidade jurídica às articulações são elementos estratégicos na atuação em rede. É primordial considerar o grau de institucionalização de todas as organizações envolvidas para arquitetar desenhos jurídicos que permitam melhor captar recursos, geri-los e implementar projetos e programas de forma inclusiva, visando mecanismos que facilitem a governança compartilhada das ações da rede e que não onerem demasiadamente os membros com menor capacidade organizacional.

Como não existe nenhum quadro legal adaptado às redes (JMJ Angola, 2009) a formalização é considerada uma boa prática em diversos casos, uma vez que é um critério básico para obtenção de financiamento. Além disso, algumas redes têm buscado registros facultativos perante o Poder Público a fim de obter maiores vantagens, como a facilitação na captação de investimentos privados, obtenção de uma maior diversidade de financiamentos, acesso a benefícios fiscais e a recursos públicos. Por exemplo, dentre as redes estudadas, 3 possuíam registro facultativo como Organização da Sociedade Civil de Interesse Público (OSCIP).

JMJ Angola (2009) assinalam que a formalidade não deveria ser um critério de financiamento tão rígido, já que 
muitas organizações preferem permanecer informais em função do receio, por parte dos membros, de que a formalização venha associada a restrições/exigências em sua atuação. Essa apreensão é mais presente nas pequenas organizações, uma vez que costumam ter dificuldade em cumprir exigências legais por possuírem recursos restritos e muitas vezes operarem fora dos ditames legais. Em termos de pesquisa, isso acarreta na dificuldade em obter informações sobre essas experiências em particular, que geralmente atuam in loco.

\subsubsection{Formas de gestão}

Em razão de exigências legais, as organizações que possuem personalidade jurídica devem ou podem possuir certas instâncias de gestão, cada qual contendo competências também especificadas por lei. Por exemplo, são instâncias obrigatórias às Associações a Assembleia Geral e Diretoria; são facultativas o Conselho Administrativo e o Conselho Fiscal. Há, ainda, certos cargos específicos para cada instância de gestão. Normalmente, compõem a Diretoria o cargo de Presidente, Vicepresidente, Secretário-geral, Secretário adjunto e de Diretor Financeiro. A Assembleia Geral é geralmente composta por representantes dos membros da rede.

Embora haja algumas variações de nomenclatura, a maioria das redes estudadas segue a estrutura de gestão descrita em lei, sem consideráveis inovações, sendo que até mesmo as organizações que não possuem personalidade jurídica, dotadas de grande flexibilidade neste quesito, acabam por reproduzir em parte essas mesmas estruturas gestoras. Quanto às redes que apresentaram alguma inovação em relação à forma de organização, destaca-se a adoção de um Conselho de Ética, Grupos de Facilitação, Grupos de Trabalho, Período de Transição e Grupos Focais.

Para além das instâncias de gestão e os cargos nelas contidos, as redes podem possuir uma equipe técnica própria. Enquanto algumas experiências apresentaram equipes técnicas próprias sem grandes especificidades, outras se destacaram por apresentarem funções diferenciadas, como equipe multidisciplinar itinerante, temática ou territorial.

As equipes multidisciplinares itinerantes possuem uma composição fixa, porém se deslocam territorialmente de acordo com a demanda da rede. A interface do trabalho de profissionais advindos de várias áreas do conhecimento proporciona diferentes pontos de vista sobre um mesmo problema, com maior potencial criativo, facilidade na troca de informação e desenvoltura. Já as equipes organizadas tematicamente apresentaram perfil especializado em uma determinada área (ex: equipe de georreferenciamento, de informática, de documentação, de desenvolvimento institucional e de comunicação e relacionamento).

A natureza de composição das equipes técnicas reflete no perfil de atuação das redes estudadas. As redes que possuíam equipe técnica temática, territorial e multidisciplinar apresentaram um perfil de governança voltado à implementação de ações em nível de rua e com uma dimensão territorial afunilada. No que diz respeito às redes que possuem equipes técnicas sem grandes especificidades, estas eram marcadas por um modus operandi mais difuso, ou seja, focadas em uma governança em nível de articulação político.

\subsubsection{Composição dos membros}

Este tópico tem por objetivo descrever quais são as principais práticas das redes estudadas quanto à composição de suas malhas, ou seja, quais são os critérios de adesão e manutenção dos atores na rede. As entidades, de forma a garantir seus interesses, criam mecanismos de entrada e manutenção dos membros por meio da formulação de critérios de composição. Esses critérios foram divididos em dois tipos: (a) quanto aos requisitos para adesão à rede e (b) quanto às ações de incentivo ao engajamento e à permanência.

No geral, as redes estudadas exigem que, para serem membros, as OSCs devem ter convergência com os objetivos e princípios da rede. Além desse critério inicial, algumas experiências acrescentam a afinidade temática como requisito. Outra 
forma de seleção de associados refere-se à natureza da instituição. Algumas experiências não admitem enquanto membro organizações sindicais, partidos políticos, empresas ou entidades vinculadas a igrejas.

Já outras iniciativas exigem dos membros CNPJ, Estatuto ou Contrato Social. Há, ainda, aquelas que impõem que os membros sejam, eles próprios, beneficiários da rede. Para tanto, essas experiências preveem a participação efetiva desse público nos espaços de discussão, articulação e formulação de projetos. O programa Iniciativa Comum, coordenado pelo Bloco Brasil da RedAmérica, por exemplo, restringe ligações com partidos políticos e com projetos com fins lucrativos, e não aceita entidades que não tenham personalidade jurídica (assim como o MEB e a Cáritas).

Outras redes vão em sentido oposto ao não estabelecerem restrições específicas de admissão aos membros, ressaltando, por exemplo, a participação estratégica de entidades religiosas e empresariais; é o caso da Visão Mundial e do GIFE. Tal prática amplia a capacidade da organização de diversificar suas fontes de financiamento e angariar recursos.

Em relação às ações realizadas pelas redes visando incentivar e engajar seus membros em torno de um objetivo comum, destacam-se iniciativas de distinção dos membros por tempo de permanência - em que organizações exigem a atuação dos interessados por determinado período para que venham a se tornar efetivamente membros - ou pela atribuição de status diferentes aos membros, o que pode ser feito por meio de condecorações a projetos ou atores que de alguma forma se destacaram. Essas homenagens, que buscam o reforço da incidência sócio-política dos associados, podem ser simbólicas, remuneradas ou associadas ao poder de voto na rede.

\subsubsection{Comunicação e transparência}

A comunicação e transparência das organizações pode ser entendida por meio de duas dimensões: instrumentos usados para disseminação de informações (meios, digitais ou não, utilizados para dar publicidade e/ou promover interação entre as redes e os interessados e/ou entre os integrantes das redes) e conteúdo veiculado (natureza das informações disponibilizadas).

Quanto aos instrumentos utilizados, além do sítio eletrônico institucional, algumas experiências destacam-se por estarem mais inseridas nas redes sociais - Facebook, Twitter, Linkedin, YouTube, Instagram - ou por fazerem uso de instrumentos mais específicos, normalmente melhor apropriados pelas redes mais institucionalizadas e recorrentes nas redes de caráter local.

Considerando a amostra estudada, 90\% possuem Facebook, $80 \%$ Twitter, 65\% YouTube, 20\% Linkedin e 10\% Instagram. Há, ainda, as que utilizam instrumentos mais específicos para promoção de comunicação e transparência, como 0800, espaço online para debate, editora própria, Jornais Informativos ou Newsletters, canais de TV e Rádio etc. (vide Quadro $1)$. 
Quadro 1. Instrumentos de comunicação e transparência.

\begin{tabular}{|c|c|c|c|c|c|c|c|c|}
\hline \multirow{2}{*}{ OSCs } & \multicolumn{5}{|c|}{ Redes Sociais } & \multicolumn{3}{|c|}{ Instrumentos específicos } \\
\hline & Facebook & Twitter & Instagram & Youtube & Linkedin & Blog & Google+ & Outros \\
\hline ABONG & & & & & & & & \\
\hline Alianza Latina & & & & & & & & \\
\hline Cáritas & & & & 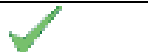 & & & & 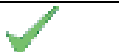 \\
\hline Criança Segura & 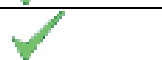 & 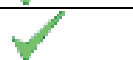 & $Y$ & 7 & & & & 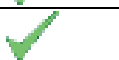 \\
\hline FGEB & & & & & & & & \\
\hline FIP & & & & & & & & \\
\hline Fórum Naciona & & & & & & & & \\
\hline GIFE & & & & & 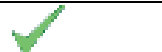 & & 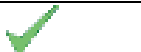 & 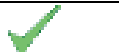 \\
\hline IEB & & $\gamma$ & & $\gamma$ & & & & 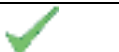 \\
\hline INESC & & 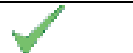 & & 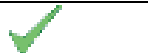 & & & & \\
\hline Iniciativa Comu & & & & & & & & \\
\hline ISA & 8 & $V$ & $\forall$ & $\checkmark$ & $\checkmark$ & $\gamma$ & 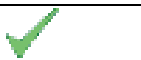 & $\checkmark$ \\
\hline MEB & 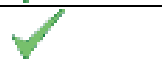 & $Y$ & & $Y$ & $Y$ & & 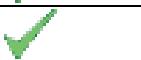 & \\
\hline Movimento Nac & & & & & & & & \\
\hline PAD & & & & & & & & 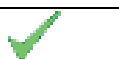 \\
\hline RNPI & 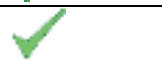 & $\checkmark$ & & $\checkmark$ & & & & $\checkmark$ \\
\hline REEVO & 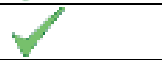 & $\checkmark$ & & & & $\gamma$ & & $\checkmark$ \\
\hline RECID & 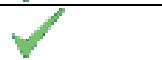 & $\checkmark$ & & $\forall$ & & & & \\
\hline StriveTogether & 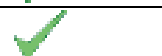 & $\gamma$ & & 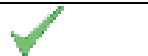 & $\checkmark$ & $\gamma$ & $\checkmark$ & \\
\hline Visão Mundial & $\checkmark$ & $\checkmark$ & & $\checkmark$ & & & $\checkmark$ & $\gamma$ \\
\hline
\end{tabular}

Fonte: Autores.

Algumas redes diferenciam-se pela pluralidade de instrumentos de comunicação que agregam, enquanto outras mostram-se pouco plurais. A variedade de instrumentos geralmente permite às organizações intensificar sua presença na sociedade, alcançando diferentes públicos e novas possibilidades de financiamento. A eficiência no uso dos instrumentos na promoção da comunicação e transparência vem atrelada a considerações sobre identidade visual, adequação do instrumento ao público-alvo e (des)centralização da informação.

A pluralidade não deve vir dissociada de uma gestão eficiente de seus instrumentos. A título de exemplo, verificou-se que entidades que são plurais em termos de instrumentos podem acabar gerando uma sobrecarga de informações ou pulverizando-as, o que pode ser ilustrado pela identificação de vários canais de Youtube de uma mesma organização. Isso pode fragilizar sua identidade e dificultar a assimilação de informações por parte dos stakeholders. Assim, as redes que apresentam poucos instrumentos podem ter a vantagem de um gerenciamento mais eficiente, uma vez que há centralização de informações.

Em relação aos conteúdos veiculados, estes são de duas naturezas: internos e externos à rede. Os externos não são produzidos pelas próprias redes, porém, em razão de interesses temáticos, são por elas difundidos. As práticas de disseminação de conteúdos externos parecem ser mais úteis para organizações que trabalham com Advocacy e que tenham um nível territorial de atuação mais amplo, ou seja, cujo foco é a sensibilização do público-alvo para com determinada causa. Os conteúdos internos, por sua vez, referem-se ao material produzido pela própria rede. De maneira geral, todas as redes possuem informações institucionais básicas, como missão, princípios, objetivos, formas de atuação etc.

A disponibilização de conteúdo interno envolve transparência tanto do ponto de vista da execução de suas atividades, quanto do ponto de vista financeiro. Há redes, por exemplo, que possuem um item exclusivo para transparência financeira em 
seu sítio eletrônico, no qual é possível consultar todos os relatórios financeiros anuais da instituição. De forma semelhante, algumas iniciativas disponibilizam, periodicamente, informativos financeiros (balanços contábeis, relatórios fiscais, demonstrações contábeis, relatórios de atividades semestrais e anuais etc.) com o objetivo de apresentar aos gestores o andamento da execução financeira, o desempenho dos recursos institucionais, bem como informações sobre alterações em projetos.

\subsection{Sustentabilidade Financeira}

A sustentabilidade financeira diz respeito às formas de obtenção de recursos para operacionalização das redes. De forma geral, algumas delas são dotadas de recursos a priori, ou seja, desde sua constituição; e outras necessitam encontrar meios de captar recursos a posteriori para exercer suas atividades. Fundações e Fundos são organizações que possuem recursos desde sua constituição. A dotação de recursos a priori ou a posteriori consiste na primeira expressão do grau de estabilidade financeira da organização para realização de suas atividades. Organizações dotadas de recursos a priori possuem fontes de recursos estáveis e permanentes desde seu nascimento, enquanto as dotadas de recursos a posteriori necessitam buscar por fontes de recursos, sendo estas, por vezes, instáveis e temporárias.

Há redes que se financiam a partir de várias fontes: contribuições espontâneas de sócios; serviços prestados; verbas de convênios ou subvenção do poder público; cooperação com entidades nacionais e internacionais; doações de pessoas físicas e jurídicas; além de aplicações financeiras e de um Fundo de Reserva. Além disso, há redes que mantêm, de forma concomitante, parcerias com um grande número de financiadores. Dentre estes, estão agências de cooperação e fundações internacionais, fundações e empresas nacionais, embaixadas e Nações Unidas. Em contraposição, redes com pouca diversificação de fontes acabam dependendo mais fortemente de uma ou poucas fontes individuais para financiar suas atividades, o que pode acarretar eventuais problemas financeiros caso alguma delas seja suspensa.

Redes enquadradas como OSCIPs, por outro lado, possuem uma maior versatilidade em pleitear recursos junto ao Poder Público. Mais especificamente, a qualificação de OSCIP lhes permite usufruir de incentivo fiscal a doações por meio da dedução do Imposto de Renda das pessoas jurídicas doadoras, receber certos bens disponíveis administrados pela Receita Federal, bem como celebrar Termos de Parceria com o Poder Público. Nesse aspecto, instituições com titulação de OSCIPs apresentam um leque maior de possibilidades de financiamento.

Uma organização em especial, a Fundação Grupo Esquel Brasil, destaca-se por possuir um mecanismo de retroalimentação de projeto baseado na aplicação do conceito de economia solidária e na prática de formação de fundos solidários. A retroalimentação consiste em fomentar determinados empreendimentos por meio do recurso advindo de Fundo Rotativo. Como mecanismo de manutenção, os grupos produtivos apoiados se comprometem a contribuir com uma parte do lucro do seu empreendimento para o próprio Fundo que os beneficiou. Assim, os recursos do Fundo ficam à disposição das comunidades para apoiar novos empreendimentos de outras famílias. Dessa forma, o Projeto alcança sua sustentabilidade depois do encerramento dos convênios e oferece aos participantes uma prática solidária na utilização do crédito.

Adicionalmente, há casos que se diferenciam por realizar o financiamento de suas atividades por meio de dois mecanismos: a parceria de apoio a programas e a parceria setorial. A primeira consiste na contribuição financeira vinculada a programas e a segunda está vinculada a projetos específicos, sendo os projetos parte de seus programas. Com esse modelo, a rede consegue atrair tanto os financiadores interessados nos seus programas mais amplos, como aqueles com interesse em um projeto específico.

Outras organizações recebem investimento social privado, ou seja, repasse de recursos privados de forma planejada, monitorada e sistemática. Fazem parte desse modelo as ações sociais protagonizadas por empresas, fundações e institutos de origem empresarial ou instituídos por famílias, comunidades ou indivíduos. Além disso, também responsabilizam os seus 
membros pela manutenção da rede, por meio de contribuições compulsórias ou voluntárias.

\subsection{Programas, Projetos e/ou Ações}

Programas, projetos e/ou ações podem ser considerados a ponta final da atuação das articulações, ou seja, quais iniciativas, de fato, as redes implementam e como são operacionalizadas. Nesse sentido, cinco programas evidenciaram-se quanto à Produção e disseminação de informações: a Plataforma "WIKI"; o Mapa Coletivo; o Programa Sinapse; e o Modelo de Incidência Política Baseada em Dados. A Plataforma "WIKI" é destinada a reconstruir e coletar artigos de conhecimento livre sobre educação alternativa. Basicamente, trata-se de coletar, produzir e/ou escrever textos breves que descrevam, expliquem e/ou desenvolvam um tema relacionado com o objetivo da rede. Assim como em outros espaços "Wiki", os artigos são produzidos, editados e corrigidos em colaboração por todos os participantes. Podem produzir esses conteúdos educadores e pessoas em formação em pedagogia ou carreiras correlatas com educação e ciências sociais.

O Mapa Coletivo busca refletir múltiplas iniciativas de educação alternativa no mundo. O Mapa é uma ferramenta que visa facilitar que pessoas e organizações encontrem umas às outras, conheçam as experiências que existem, formas de pensar, histórias, características e desafios. No sítio eletrônico do Mapa, é possível filtrar as experiências por: tipo (educação formal, educação não formal, educação superior, organizações, grupos e eventos); enfoques alternativos (educação progressista, educação livre/libertária, educação democrática, educação holística, educação popular, etnoeducação e educação sem escola); métodos pedagógicos (Montessori, Waldorf, Reggio Emilia, Pikler e outros métodos); e gestão (estatal, privada, social, comunitária e charter).

O Programa Sinapse é um hub de conhecimento, ou biblioteca virtual, que visa reunir publicações relevantes em uma única plataforma, de modo a facilitar o acesso ao material produzido pelo campo de forma gratuita e promover o compartilhamento de conhecimento entre investidores sociais e outros atores da sociedade civil.

Por fim, o Modelo de Incidência Política Baseada em Dados consiste em uma ferramenta de cunho quantitativo usada no monitoramento de políticas e na divulgação de informações. A metodologia tenta aprofundar aspectos básicos para o desenvolvimento de sistemas de informação e monitoramento de políticas baseando-se na utilização de dados estatísticos para dar visibilidade ao tema de atuação da rede. A ferramenta também tem por escopo avançar na articulação das experiências num processo de aprendizagem mútuo.

Em relação à Participação e formação do público-alvo, destacam-se duas iniciativas: a de formação de multiplicadores e a de participação do beneficiário. Multiplicadores são comunicadores treinados para disseminar determinada causa nas comunidades de interesse, podendo ser profissionais de saúde, educação, trânsito, agentes comunitários ou gestores de entidades públicas com ou sem fins lucrativos. O conteúdo é transferido para esses atores de duas formas: em formações presenciais, como palestras e oficinas, e cursos a distância pela internet. A metodologia tem como objetivo empoderar e engajar os cursistas para que promovam mudanças sociais. Já os programas que investem na participação do beneficiário na rede aplicam metodologias específicas, que englobam o uso de ferramentas de interação, animação e reflexão, como gincanas, rodas de conversa e palestras dialogadas.

Em relação à sustentabilidade dos programas, o destaque é para o Fundo Iniciativa Comum, desenvolvido entre 2010 e 2013, resultado da parceria entre o Bloco Brasil da RedEAmérica e a Fundação Interamericana. O objetivo geral foi o desenvolvimento de capacidades dos grupos e organizações das populações de baixa renda em se autoconvocar, definir e lutar por suas necessidades. Tratou-se, assim, de uma ação voltada ao protagonismo dos beneficiários finais. Embutido nesse objetivo, estava a busca pela formação de grupos independentes que possam atuar de forma cidadã e autônoma, impactando as comunidades em que habitam. Para tanto, o Fundo lançou editais convocando coletivos para receberem recurso e implementarem seus projetos. Convocar os coletivos fez parte da tentativa de promoção dos espaços que realmente atraíssem 
os jovens. A ação da Iniciativa Comum foi a de qualificar os coletivos por meio do fornecimento de ferramental e conhecimento, de tal forma que, uma vez organizados, tivessem condições de perseguir seus objetivos com maior desenvoltura.

Além disso, o programa propôs uma solução inovadora para a dificuldade de localizar e contatar esses potenciais jovens parceiros: buscar redes de coletivos que já tinham acesso aos jovens e, assim, ganhar capilaridade nos territórios. Ao chamar as redes para apresentar projetos de fortalecimento de coletivos juvenis, a Iniciativa Comum também ajudou a catalisar ou a concretizar processos de desenvolvimento que já estavam em andamento: já havia os grupos, já existiam as redes, mas todos tinham dificuldade de se articular. Propositalmente, o edital da Iniciativa Comum não limitou ou definiu previamente os temas a serem trabalhados pelos coletivos jovens. As únicas restrições eram de caráter legal - por exemplo, os projetos não poderiam fazer apologia ao uso de drogas - ou partiam de regras das instituições envolvidas no convênio do Fundo - os projetos não poderiam ter fins lucrativos ou ligação a partidos políticos. Já existia forte comprometimento com as causas locais, o que faltava era capacitação para o trabalho sistematizado e melhor aproveitamento das ferramentas. Com a Iniciativa Comum, as redes se tornaram planeadoras, gestoras, executoras e avaliadoras do processo: criaram métodos de trabalho, apoiaram e monitoraram o trabalho de outros agentes.

A Poupança Coletiva é uma iniciativa que promove a organização de grupos produtivos e de poupança coletiva em prol de uma causa. Já foram desenvolvidas ações nesse sentido que buscaram melhorar o sustento de famílias e impactar diretamente no bem-estar de crianças por meio da promoção de capacitações, atividades de educação financeira e empreendedorismo com adultos.

O Fundo Rotativo Solidário visa fomentar pequenos empreendimentos produtivos para pessoas de baixa renda que não têm acesso ao microcrédito, ou a outras fontes de financiamento. O público-alvo do projeto são os líderes voluntários, famílias acompanhadas pela Pastoral da Criança e jovens de baixa renda. O Projeto seleciona pessoas desempregadas com potencial empreendedor, organiza essas pessoas em grupos e os apoia na elaboração de um plano de negócios. Além disso, oferece um pequeno financiamento inicial para os miniempreendimentos produtivos, bem como capacitação, assessoria e apoio na comercialização de produtos.

Por último, os Fundos Solidários, também conhecidos como Fundos de Solidariedade, mais do que mecanismos de financiamento de projetos, são instrumentos da economia comunitária a serviço do desenvolvimento local, visto que os projetos sociais devem cumprir um papel de fortalecimento das organizações locais, das dinâmicas geradoras do desenvolvimento comunitário, econômico e social. Os Fundos Solidários têm caráter pedagógico, não assistencialista, pois agregam processos de formação cidadã para ampliação e conquista de direitos às ações de desenvolvimento, e tecem laços de solidariedade no que tange à priorização das regiões mais empobrecidas e necessitadas.

\section{Discussão dos Resultados}

Os resultados comparativos das 20 experiências estudadas permitiram traçar perfis de atuação em rede, cujas dimensões (organização institucional; sustentabilidade financeira; e programas, projetos e/ou ações), tratadas anteriormente de forma dissociada, serão agora abordadas numa perspectiva analítico-conceitual. Para tanto, a Figura 3 ilustra a atuação das organizações quanto aos níveis de governança estratégica e de atuação de base, o que se chama de Matriz Situacional (Figura $3)$. 
Figura 3. Matriz situacional aplicada.

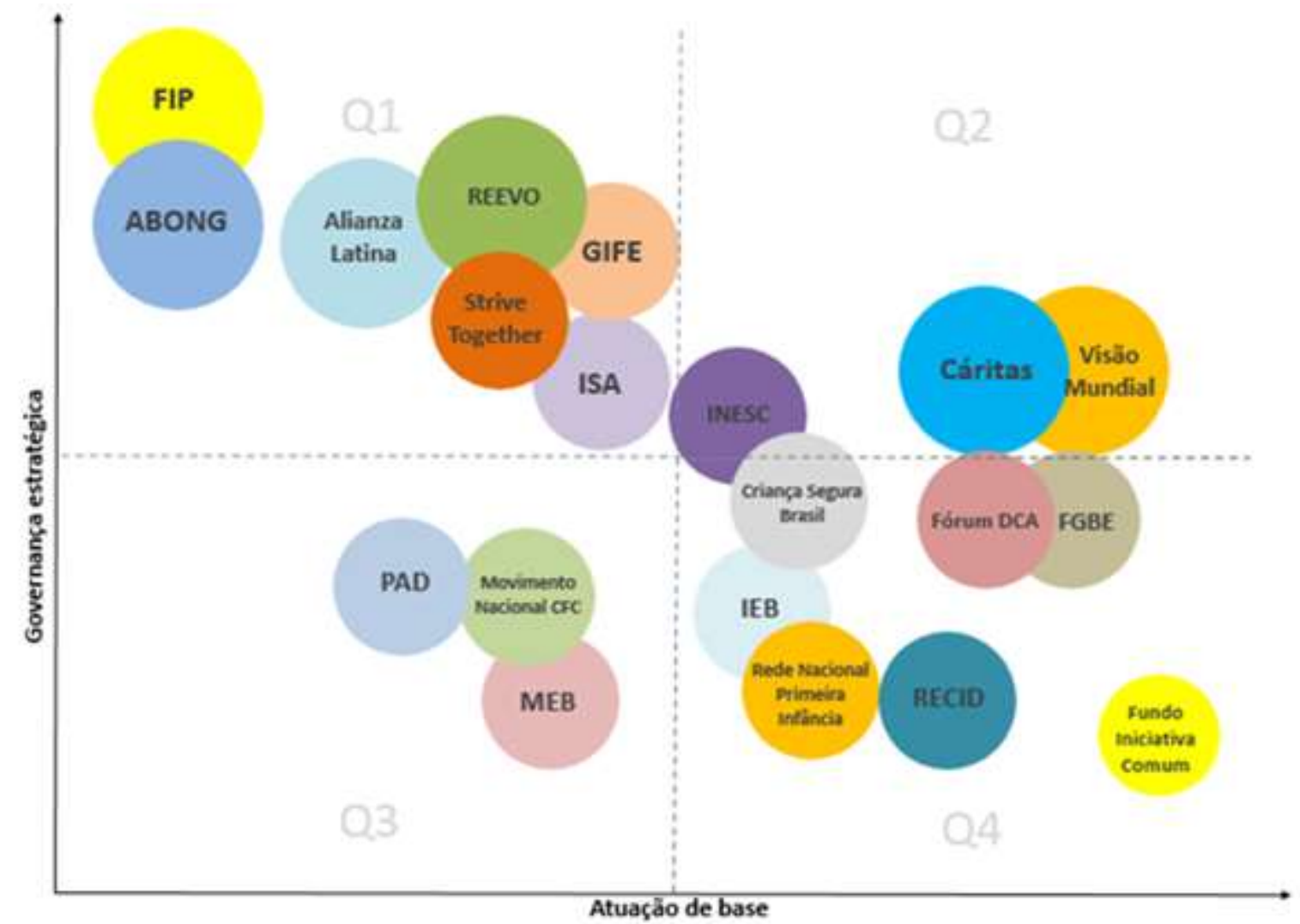

Fonte: Autores.

O eixo vertical, de governança estratégica, retrata as redes a partir dos níveis de maior ou menor incidência política, principalmente no campo da articulação das OSCs. Experiências com governança estratégica direcionada à incidência política são aquelas cujo foco de atuação se dá na sensibilização e mobilização do público-alvo para com determinada causa. No extremo superior, encontram-se aquelas com atuação fortemente direcionada à incidência política na regulação do setor, enquanto no extremo inferior estão representadas as redes de baixa incidência.

No que diz respeito ao eixo horizontal, de atuação de base, considera-se o nível de atuação das organizações na implementação de programas, projetos e/ou ações em nível de rua ou in loco. Quanto mais à direita, mais as organizações trabalham na interface operacional da rede, implicando em um relacionamento mais direto com seu público-alvo. Quanto mais à esquerda, menos atuantes são as organizações nesta perspectiva.

Tecnicamente, a distribuição das organizações entre os eixos foi feita numa perspectiva comparada, ou seja, foram inseridas as organizações situadas nos extremos dos dois eixos e, após, distribuídas as demais organizações. Os extremos comparativos utilizados foram as experiências do Fórum Internacional de Plataformas Nacionais de ONGs (FIP) e da Iniciativa Comum. O FIP foi escolhido por ser a maior organização da amostra, atuante politicamente na regulação do setor, sendo o limite superior do eixo de governança estratégica. O Fundo Iniciativa Comum, por se tratar de um programa de base, circunscrito territorialmente e voltado diretamente para implementação de ações, foi estabelecido como limite-direito do eixo atuação de base. Além disso, as experiências estão representadas na figura com tamanhos distintos a partir de sua dimensão de atuação: internacional; nacional; e regional.

A distribuição das organizações entre os eixos, utilizando-se dos critérios acima explicitados, permitiu perceber que as organizações se aglomeraram em um ou outro quadrante de acordo com suas determinadas características, formando grupos 
que, depois de uma análise mais detalhada, mostraram refletir certo padrão de práticas. Isso mostra que os vetores governança estratégica e atuação de base são elementos chave que refletem o padrão de práticas que certas organizações costumam seguir, provavelmente por estarem ligados diretamente ao escopo e à amplitude das organizações.

Nesse sentido, foram identificados quatro quadrantes que refletem o perfil de atuação das entidades neles alocadas: Perfil Regulador, Perfil Linha de Frente, Perfil Híbrido e Perfil Impreciso. O quadrante 1, Perfil Regulador, aglomera as instituições cuja atuação retrata as organizações de acordo sua capacidade de articular-se politicamente com outras organizações, mobilizando-as. Elas também costumam estar atentas à representatividade jurídica para com seus membros; possuem poucos requisitos para adesão à rede; e são dotadas, em geral, de programas no âmbito da produção e disseminação de informações qualificadas de acesso livre. Tratam-se, nesse sentido, de instituições que possuem um perfil articulador e que não costumam operacionalizar diretamente ações de base.

Via de regra, as organizações com Perfil Regulador possuem objetivos, valores e princípios mais difusos, a fim de abarcar o maior número possível de entidades na rede. Suas estratégias costumam ser voltadas aos temas da informação, comunicação e formação e, por meio de sua representatividade, buscam proporcionar melhor incidência política da rede e melhorar a capacidade de expansão de interconexões. Nesse sentido, são entendidas como nós hiperconectores, que funcionam como polos de convergência e de irradiação, por serem preferencialmente escolhidos para conexão a outros nós e dada sua própria capacidade de conectar-se ainda mais (Martinho, 2003). Sendo assim, são figuras centrais que atuam como intermediadoras na construção e manutenção dos laços entre seus membros, dada sua grande influência sobre os demais atores no que se refere ao controle das possibilidades de fluxos. Tais organizações possuem recortes amplos de atuação, geralmente de nível nacional ou internacional.

O quadrante 4, Perfil Linha de Frente, situa as organizações que trabalham na interface operacional da rede, implicando num relacionamento mais direto com o público-alvo. São instituições voltadas às ações de base, cuja principal característica é a maior conexão com o beneficiário final da própria rede, geralmente frisando a necessidade de protagonismo. Territorialmente, são marcadas por um recorte mais específico, com atuações in loco. Ademais, costumam possuir práticas voltadas à sustentabilidade de programas e à participação e formação de público-alvo. Particularmente, esta categoria vai ao encontro do que Martinho (2003), JMJ Angola (2009), Haesbert (2006) e Alvear (2008) definem como Redes Territoriais ou Geográficas, que aglutinam parceiros num espaço específico, a fim de tratar de uma diversidade de problemas enfrentados pelos mesmos.

Tais experiências apresentam objetivos, valores e princípios mais restritivos, no intuito de afunilar sua atuação e constituir laços que atendam aos seus interesses. Diferentemente das redes com Perfil Regulador, que atuam como hiperconectoras, as redes da Linha de Frente atuam com foco no aumento da densidade da rede. Assim, colaboram na criação, ampliação e manutenção das conexões diretas entre os membros. Um resultado relacionado ao aumento da densidade da rede é o aumento da sua transitividade, ou seja, quanto mais conexões entre si os membros possuírem, menor será a necessidade de intermediários para chegar de um membro até outro. Isso faz com que os membros da rede visualizem melhor as possibilidades de parcerias para proporcionar atividades coordenadas. Além disso, uma rede com um número considerável de conexões impede seu desmantelamento quando há perda de contatos, pois permite uma multiplicidade de caminhos, conferindo liberdade e flexibilidade à rede (Martinho, 2003, p. 34).

O quadrante 2, Perfil Híbrido, apresenta características que são resultado da interseção dos quadrantes 1 e 4, reunindo instituições que atuam tanto em uma perspectiva de incidência política quanto na implementação de ações de base. Com exceção da iniciativa do Instituto de Estudos Socioeconômicos (INESC), são organizações derivadas de uma versão de si próprias a nível internacional. A Cáritas Brasileira, por exemplo, é vinculada à Caritas Internationalis, e a Visão Mundial, ao World Vision International. Assim, são afunilamentos nacionais de experiências de amplitude internacional, constituídas 
justamente a fim de aumentar a capacidade de implementação in loco. Estas organizações estão preocupadas com ambos os vieses dos eixos de governança estratégica e atuação de base, possuindo um perfil voltado tanto para o protagonismo do beneficiário final, quanto para a incidência política da rede.

As organizações com Perfil Híbrido podem atuar como hiperconectoras e no aumento da densidade entre os membros da rede. São atentas à representatividade jurídica; costumam possuir poucas exigências para adesão à rede, como foco na multiplicação de suas fontes de financiamento; e são dotadas, em geral, de práticas quanto à sustentabilidade de seus programas.

O quadrante 3, Perfil Impreciso, reúne organizações que não possuem forte incidência política, tampouco são robustas na atuação de base. Ainda assim, é possível que organizações classificadas neste perfil o sejam em razão da falta de disponibilização de informações sobre a sua atuação nos sítios eletrônicos.

\section{Considerações Finais}

A análise empírica realizada com as 20 experiências de atuação em rede considerou as dimensões de Organização Institucional (que contempla natureza jurídica, formas de gestão e comunicação e transparência); Sustentabilidade Financeira; e Programas, Projetos e/ou Ações. A partir dessa análise, foi possível identificar duas principais dinâmicas na atuação das organizações: governança estratégica e atuação de base. Tais dinâmicas foram tomadas como vetores (ou eixos) para a construção de uma ferramenta para a identificação dos perfis de atuação das OSCs: a Matriz Situacional.

A ferramenta resulta de uma análise das organizações selecionadas no que diz respeito aos seus níveis de governança estratégica - representados na matriz como eixo vertical - e de atuação de base - eixo horizontal. Para a disposição das organizações nos eixos, é necessária a fixação de pelo menos duas organizações pivôs, uma para cada eixo, e, a partir daí, distribuir comparativamente as demais organizações.

Os resultados desse processo permitiram a exposição passo a passo de uma ferramenta de análise sobre articulação de OSCs, bem como a delimitação dos quatro perfis de atuação (Figura 4):

(i) Perfil Regulador - aglomera as instituições cuja atuação está fortemente direcionada à incidência política na influência da regulação do setor em que atua;

(ii) Perfil Impreciso - reúne organizações que não possuem forte incidência política, tampouco são robustas na atuação de base;

(iii) Perfil Híbrido - reúne OSCs que atuam tanto em uma perspectiva de incidência política quanto na implementação de ações de base e, em geral, são organizações derivadas de uma versão de si próprias a nível internacional; e

(iv) Perfil Linha de Frente - situa as organizações que trabalham na interface operacional da rede, implicando em um relacionamento mais direto com seu público-alvo. 
Figura 4. Modelo da Matriz Situacional.

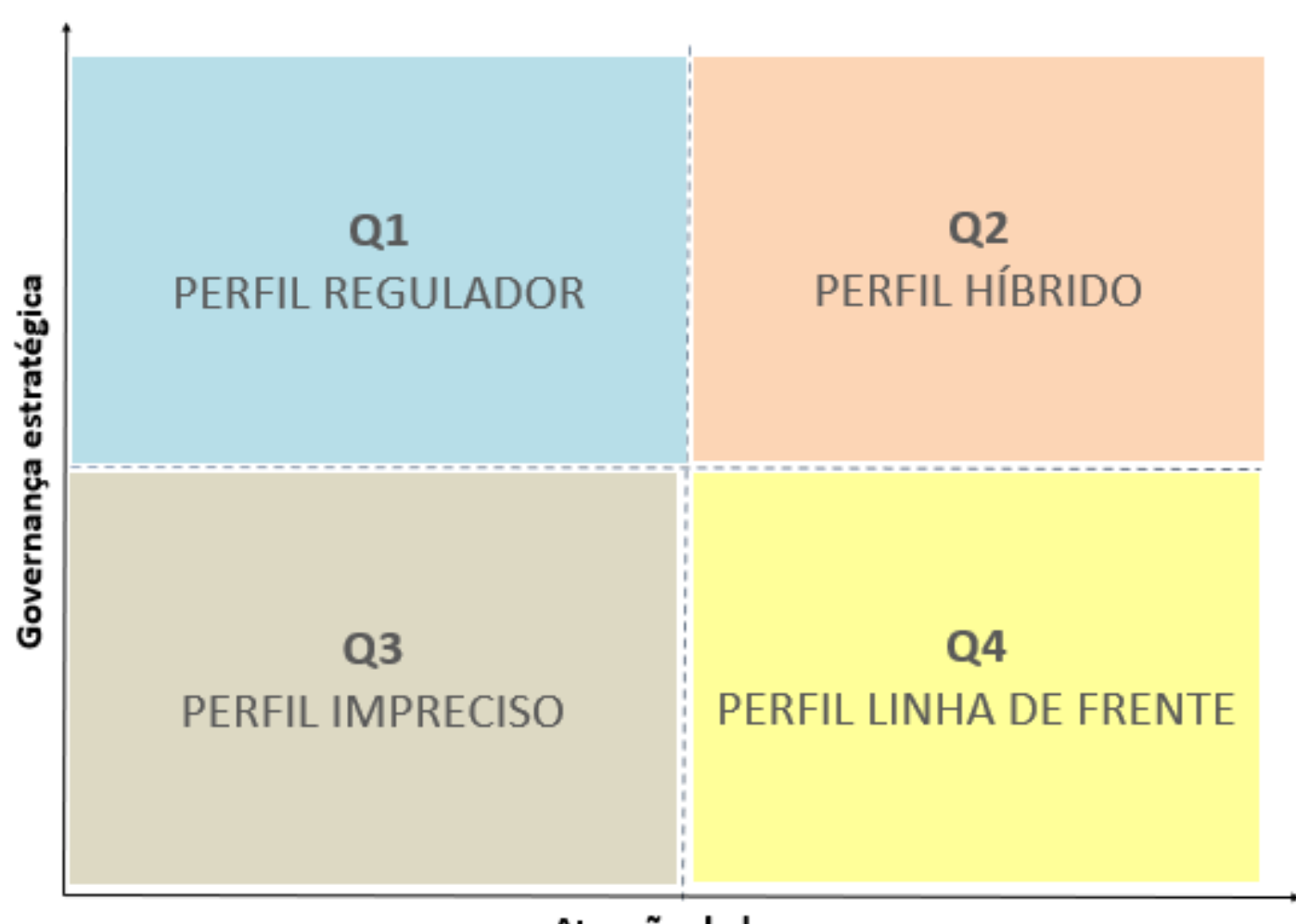

Atuação de base

Fonte: Autores.

As contribuições deste estudo são de possível interesse para três principais grupos. Para as OSCs, a matriz situacional permite uma visualização do contexto, ou seja, de mapeamento das entidades de acordo com suas características, de forma a orientá-las em decisões estratégicas, por exemplo na constituição de novas articulações. Sabendo dos perfis de seus pares, as organizações são capazes de firmar parcerias mais assertivas, que favoreçam o cumprimento de seus objetivos e, assim, fortaleçam o trabalho em rede.

Para o Poder Público, o panorama gerado pela ferramenta pode ser usado para uma distribuição mais eficiente dos recursos, identificando aquelas OSCs, ou conjunto de OSCs, que sejam dotadas das características que darão melhor capilaridade e eficiência para prestação do serviço público desejado. Além disso, a atuação Poder Público-OSCs ultrapassa as relações de fomento, podendo complementar-se. Nesse sentido, a capacidade de um governo de reconhecer o perfil das OSCs que atuam em seu território permite traçar arranjos que fortaleçam o serviço público.

Já para a comunidade acadêmica, os achados estimulam reflexões teóricas e investigações empíricas que ampliam o conhecimento sobre o fenômeno, abrindo possibilidades para estudos sobre redes em perspectivas e contextos distintos. O artigo demonstra que as organizações possuem características comuns, sendo possível agrupá-las a partir de um processo de reconhecimento de posições comparadas, culminando em arranjos interorganizacionais cuja visualização potencializa análises teórico-empíricas e possibilita o avanço no campo do conhecimento em redes, podendo ser replicado e reaplicado em outros contextos. Logo, a matriz permite escanear o ambiente para detectar mudanças, melhor interpretá-las e criar adaptações.

As limitações deste artigo são de caráter metodológico e referem-se, sobretudo, à seleção das organizações analisadas. Primeiro, porque a identificação das experiências em rede pressupôs a existência de um grau mínimo de visibilidade no ambiente online. Segundo, porque apenas foram consideradas redes voltadas para o desenvolvimento social. Essa limitação impacta, principalmente, na identificação de articulações de cunho mais territorial que, por vezes, são "invisíveis" aos 
pesquisadores. Uma possível consequência dessa limitação é que, se utilizado um conjunto de OSCs diferente, as mesmas organizações estudadas em um arranjo podem se mover de um perfil para outro, já que a matriz proposta se baseia numa perspectiva relacional, em que a comparação pode resultar em diferentes combinações. Entretanto, as limitações podem ser entendidas como um motivo para complementação dos avanços obtidos sobre a dinâmica de atuação das redes.

Trabalhos futuros podem utilizar das contribuições deste estudo para melhor avaliar a validade das características atribuídas a cada perfil, auxiliando no aperfeiçoamento da ferramenta. Especificamente, sugere-se investigar: de que forma uma organização com determinado perfil interfere na dinâmica de sua atuação e na relação com outros atores? Quais as potencialidades que a homogeneização ou hibridização de perfis em arranjos interorganizacionais pode oferecer? Que estratégias de gestão podem ser traçadas a partir da identificação dos perfis de atuação das OSCs?

\section{Agradecimentos}

O presente trabalho foi realizado com apoio da Fundação Itaú Social (FIS) e da Coordenação de Aperfeiçoamento de Pessoal de Nível Superior - Brasil (CAPES) - Código de Financiamento 001.

\section{Referências}

Alvear, C. A. S. (2008). A formação de redes pelas organizações sociais de base comunitária para o desenvolvimento local: um estudo de caso da Cidade de Deus: COPPE/UFRJ.

Amaral, V., Justen, L. M., \& Fernandes, J. C. (2003). Princípios: Organização em rede. Apresentação na Oficina para formação de facilitadores para redes de EA REASul -Rede Sul Brasileira de Educação Ambiental e REBEA - Rede Brasileira de Educação Ambiental, out.

Amundsen, I., \& Abreu, C. (2007). Sociedade Civil em Angola: Incursões, Espaco Responsabilidade. CMIReport.

Appe, S., \& Barragán, D. (2017). Policy windows for CSOs in Latin America: Looking outside legal and regulatory frameworks. Voluntas: International Journal of Voluntary and Nonprofit Organizations, 28(4), 1812-1831.

Clements, A., Darroch, P. I., \& Green, J. (2017). Snowball Metrics - providing a robust methodology to inform research strategy - but do they need help? Procedia Computer Science, 106, 11-18.

Goulart, S. et al. (2010). Articulações em rede e acontecimentos no território: subsídios teóricos para a formação de políticas públicas para o desenvolvimento. Cadernos ebape. br, 8(3).

Goulart, S., Vieira, M. M. F., Costa, C. F., \& Knopp, G. (2010). Articulações em rede e acontecimentos no território: subsídios teóricos para a formação de políticas públicas para o desenvolvimento. Cadernos ebape. br, 8 (3), 388-403.

Haesbaert, R. (2006). Territórios Alternativos. (2a ed.) Editora Contexto.

Angola, J. M. J. (2009). Mapeamento de Redes de Organizações da Sociedade Civil em Angola. Encomendado pelo Ministério do Planeamento de Angola Programa de Apoio aos Actores Não Estatais (PAANE).

Lopez, F. G. (Org.). (2018). Perfil das organizações da sociedade civil no Brasi: Ipea. 176 p.

Mañas, A. V. (2000). Um estudo sobre redes: O que as organizações precisam saber. Revista Administração em Diálogo-RAD, 2(1).

Martinho, C. (2003). Redes: uma introdução às dinâmicas da conectividade e da auto-organização. WWF.

Martinho, C. (2013). Iniciativa comum: trajetórias e aprendizados com as redes e coletivos de jovens. RedEAmerica.

Mello, J., Pereira, A. C. R., \& Andrade, P. G. (2019). Afinal, o que os dados mostram sobre a atuação das ONGs? Análise de transferências federais e projetos executados pelas organizações da sociedade civil no Brasil. Texto para Discussão, IPEA.

Mendonça, P., Alves, M. A., \& Nogueira, F. (2016). Civil society organisations and the fight for rights in Brazil: analysis of an evolving context and future challenges. Development in Practice, 26(5), 592-605.

Minhoto, L., \& Martins, C. (2001). As redes e o desenvolvimento social. Cadernos FUNDAP, 022, p. 81.

Motta, R. G., Junqueira, L. A. P., \& Turra, F. J. (2018). A eficácia das redes sociais e das ferramentas de marketing no recrutamento de integrantes para organizações sem fins lucrativos. Revista Pensamento Contemporâneo em Administração, 12(1), 76-88.

Newman, M. E. J. (2003). Ego-centered networks and the ripple effect, Social Networks, 25 pp. 83-95.

Olivieri, L. (2003). A importância histórico-social das redes: Rede de informações para o terceiro setor. Enanpad, 31, 1-17. 
Research, Society and Development, v. 10, n. 1, e59010112108, 2021

(CC BY 4.0) | ISSN 2525-3409 | DOI: http://dx.doi.org/10.33448/rsd-v10i1.12108

Pereira A. S. et al. (2018). Metodologia da pesquisa científica. Ed. UAB/NTE/UFSM.

Souza, Q., \& Quandt, C. (2008). Metodologia de análise de redes sociais. O tempo das redes. O Tempo das Redes: Perspectiva, 31-63.

Stefani, M. T., \& Junqueira, L. A. P. (2012). Redes e parcerias-uma reflexão sobre a relação entre o governo municipal e uma organização não governamental. NAU Social, 3(5), 157-174.

Stephen, J. (2011). Management of civil society organisations (CSOs): A case study of selected CSOs in Tanzania.

Vogt, W. P., \& Johnson, B. R. (1999). Dictionary of Statistics and Methodology: A Nontechnical Guide for the Social Sciences: Sage. 437. 